\title{
Our Inaugural Issue
}

\author{
Norman E. Taylor*
}

Inaugural: Marking a beginning; first in a projected series.

Collaborate: To work with another person or group in order to achieve or do something.

-Miriam Webster 2016

The latter of these definitions conveys both the fundamental character and the driving ambition of our Journal of CSWB. The former challenged us. If we are to truly mark our beginning and have that beginning foreshadow the continuing series to come, we need to launch the Journal with an opener that strikes all the right notes, like any good overture foretells the plot. We hope we have come close.

I will begin by acknowledging the great work of our editorial board in this achievement. We look forward to a time when the articles flow with regularity into our website, and when our challenge shifts to keeping pace with a growing body of knowledge, experience, and science in collaborative, multi-sector approaches to community safety and well-being. This will take time. In the meantime, our section editors have - and will continue to - mine their varied networks. We are confident that more and more authors and would-be authors will begin to recognize the unique channel this Journal provides them, and our readers will find in our diverse mix of articles the continuing reinforcement of a central premise: you cannot collaborate in isolation.

And so, I will continue by thanking our first group of published authors for their generous contribution of ideas that matter. Collectively, you have signaled the storyline of our Journal.

Our opening issue features eight strong and varied articles, ranging from scholarly entries to practitioner perspectives, with some policy-challenging works landing somewhere in between. The issue features research articles including original, review, and preview. It features social innovation narratives designed to stimulate dialogue and to open policy-makers to new considerations. And, one article probably best meets the definition of a practice guideline, though it does so with innovation at its core.

Our goal was to have something for everyone in this first outing. And, while that might be overstating things a bit, we do offer here a selection that should serve some particular interests among researchers, policy-makers, organizational managers, and front-line professionals. Researchers will certainly be drawn to the Wilson, Guliani, \& Boichev review paper that makes a strong case for much needed evidence about the hard and soft costs of occupational stress injuries among first responders. No doubt, there is much in that article that should be of real concern to every category of reader. On a related theme, the Coleman \& Cotton team continues their national leadership in raising a call for more strategic approaches to dealing with mental health issues and related training in police organizations, and more explicitly, in their resulting external interactions with members of the public.

The two Chrismas papers, one a narrative and the other a research preview, both strike directly into our editorial themes about vulnerable populations and our need to better understand how the system can better respond to the evident risk factors and dynamics that make them so. And the Johnson-Way \& O'Sullivan entry expands our awareness of the burdens of crime and social disorder that are carried disproportionately by victims on the one hand and, on the other hand, outlines the tremendous potential that exists from bringing the victimization lens more directly into CSWB policy-making and practice.

Gossner, Simon, Rector, \& Ruddell deliver a rich and compelling piece of original research that provides strong evidence that recidivism can indeed be measurably reduced through the proper application of effective case management practices and, in particular, practices which exemplify collaboration among multiple parts of the system.

CSWB practitioners in all sectors will find considerable appeal in the Hawkes paper, outlining the commitment the Ontario Provincial Police are making to collaborative and risk-driven approaches right across that province. And similarly, in the Baker article, we get to share in the personal reflections of a career educator who, in his final year of service, both witnessed and helped to drive the adoption of the Situation Table, a risk-driven intervention collaborative set up in a semi-rural Ontario county, modelled on the original and widely documented Prince Albert Hub.

If you are sensing in this mix a storyline that is unpredictable, complex, and sometimes contradictory in its devices, then we have achieved what we hoped for: a beginning. Please join in.

\section{AUTHOR AFFILIATIONS \\ *Editor-in-Chief, Journal of Community Safety and Well Being.}

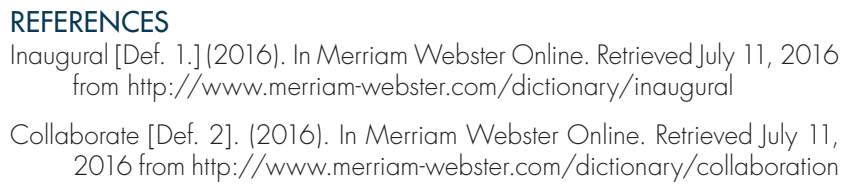

